EDITORIAL REVIEW ARTICLE

\title{
Obesity Hypoventilation Syndrome
}

\section{J. M. Joshi}

Department of Respiratory Medicine, T. N. Medical College, BYL Nair Hospital Mumbai

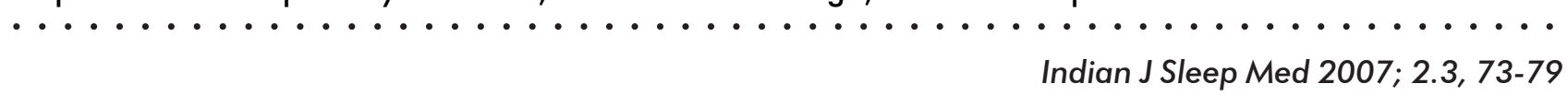

Keywords : Sleep hypoventilation, Pickwickian Syndrome, Sleep disorder breathing

\section{Introduction}

$\mathrm{O}$ besity, an epidemic in the 21 st century was introduced into the international classification of diseases half a century ago. (1) Obesity is defined as an accumulation of excess body fat, to an extent that may impair health. A crude measure of excess fat is the body mass index (BMI), a person's weight (in kilograms) divided by the square of his or her height (in metres). WHO defines overweight as a BMI of 25 or more, and obesity as a BMI of $>30 \mathrm{~kg} / \mathrm{m} 2$ and extreme obesity, BMI $>40 \mathrm{~kg} / \mathrm{m} 2$. (2) Globally in 2005 , approximately 1.6 billion adults were overweight and at least 400 million adults were obese. WHO further projects that by 2015 , approximately 2.3 billion adults will be overweight and more than 700 million will be obese. In the United States, a third of the adult population is obese, and from 1986 to 2000, the prevalence of BMI of $40 \mathrm{~kg} / \mathrm{m} 2$ has quadrupled, and that of BMI of $50 \mathrm{~kg} /$ $\mathrm{m} 2$ has increased by fivefold. (3) Once considered a problem only in high-income countries, obesity is on the rise in low- and middle-income countries, particularly in urban settings. Changes in diet, coupled with increasingly inactive lifestyles, have led to major epidemics of obesity in several Asian countries including India. (4) The obesity epidemic is not only impacting adults, it is a global phenomenon affecting children and adolescents. (5)

Address for correspondence:

Dr. J M Joshi

Professor and Head

Dept of Respiratory Medicine

BYL Nair Hospital

Mumbai 400008

Email drioshijm@email.com,drioshijm@gmail.com

Tel no/ Fax No: 91-022-23003095
Obesity is associated with arterial hypertension, coronary artery disease, diabetes mellitus and degenerative joint disease. Recently, there has been an increased awareness pulmonary consequence of obesity as a major source of morbidity. Obese patients also have compromised respiratory function while awake and upright. Their ventilatory functions worsen in supine position and when they sleep. Obese patients demonstrate various breathing abnormalities in sleep (6) obstructive apnoeas and hypopnoea; obstructive hypoventilation due to increased upper airway resistance; and central hypoventilation. In addition to the sleep related breathing disorders, some obese patients hypoventilate while awake, exhibiting a partial pressure of carbon dioxide (PaCO2) greater than $45 \mathrm{~mm} \mathrm{Hg}$ accompanied by sleep disordered breathing or sleep apnoea and this is called the obesity - hypoventilation syndrome (OHS). Patients with OHS display a worse prognosis than patients with obstructive sleep apnoea (OSA) (7) and use more health-care resources (8).

The definitions of overweight and obesity is based on epidemiological studies in the developed countries. Preliminary information from developing nations suggests that lower cut-off levels for both BMI and waist circumferences are necessary for populations who are at particular risk from comparatively modest degrees of overweight. (9) The 'Asian Indian Phenotype' characterized by less of generalized obesity as measured by body mass index (BMI) but greater central body obesity as shown by greater waist circumference (WC) and waist-to-hip ratios (WHR). This leads to unique biochemical and hormonal changes including higher plasma insulin levels, greater insulin resistance, lower HDL cholesterol, higher triglyceride levels, increased small dense LDL cholesterol as well as small dense HDL cholesterol and C-reactive protein and leptin levels but

Indian Journal of Sleep Medicine (IJSM), Vol. 2, No. 3, 2007 
decreased adiponectin levels. Thus many Asian Indians are "metabolically obese" and may have a higher prevalence of OHS. (10)

\section{Historical Perspective}

The first historical description of OHS is by Charles Dickens in 1837, who described "Joe" a fat, somnolent coach boy in "The Posthumous Papers of the Pickwick Club". (11) After 119 years, in a case report titled "Extreme Obesity Associated With Alveolar Hypoventilation a Pickwickian Syndrome" (12), reported the case of a 51-year-old business executive, 5 feet 5 inches and weighed $118 \mathrm{~kg}$. He played poker and on one occasion was dealt a hand of three aces and two kings, but "he failed to take advantage of this opportunity because he had dropped off to sleep". The term obesity - hypoventilation syndrome OHS (13) was used in 1955 by Auchincloss and colleagues in patients with obesity, daytime hypercapnoea and hypoxemia, polycythemia, hypersomnolence and right ventricular failure. This syndrome gained attention among general physicians after Bickelmann et al described it as the "Pickwickian syndrome" (14).

\section{Definition}

Thus, obesity-hypoventilation syndrome (or alveolar hypoventilation in the obese) is defined as chronic alveolar hypoventilation $(\mathrm{PaO} 2<70 \mathrm{mmHg}, \mathrm{PaCO} 2>45$ $\mathrm{mmHg}$ ) in obese patient with a body mass index $>30$ $\mathrm{kg} / \mathrm{m}$ who have no other respiratory disease explaining the gas anomalies. (15) Recently published definition of OHS (16) use the following criteria: 1) extreme obesity (body mass index (BMI)_30 kg/m2); 2) excessive daytime sleepiness; 3) chronic daytime hypercapnoea (arterial carbon dioxide tension $(\mathrm{PaCO} 2) \_45 \mathrm{mmHg}$ ); and 4) severe OSA (apnea-hypopnea index (AHI) _30/h or severe oxygen desaturation).

\section{Epidemiology}

The exact prevalence of OHS in the general population is not known but one-fifth of patients with OSA also have OHS (6). The estimated prevalence of OHS among patients with OSA is reported between $10 \%$ and $20 \%$ but is likely to be higher in the subgroup of patients with extreme obesity (i.e., BMI _ $40 \mathrm{~kg} / \mathrm{m} 2$ ). (17) There is no clear racial or ethnic predominance. Because of cephalometric differences, OHS associated with OSA occurs at a lower BMI in Asians compared to whites. (18) The impact of "metabolic obesity" on prevalence of OHS in these populations is yet to be studied.

\section{Pathophysiology}

Obese sleepy patients fall into 2 categories

a) Those with the sleep-related breathing disorders or sleep apnoea syndromes most common OSA and

b) Those with sleep-related breathing disorders with awake hypoventilation

\section{Sleep-related breathing disorders in OHS}

Since most patients with OHS display repeated upper airway obstruction during sleep, OHS has been considered as the most severe type of OSA, hence the term hypercapoeic OSA has also been used to describe OHS. However, a small number of patients with OHS do not experience sleep apnea (19) but demonstrate sleep hypoventilation, defined as an increase in $\mathrm{PaCO} 2$ during sleep by $10 \mathrm{~mm} \mathrm{Hg}$ above wakefulness or a significant oxygen desaturation that is not explained by obstructive apneas or hypopneas. This syndrome is termed the sleep bypoventilation syndrome (SHVS).

\section{Awake hypoventilation in OHS}

It is unclear why some morbidly obese individuals have waking alveolar hypoventilation while others with similar obesity do not. Obesity may not be related with development of daytime hypercapnoea alone, as BMI shows no significant correlation with $\mathrm{PaCO} 2$ in OHS. Body weight per se does not correlate with chronic daytime hypercapnoea, though weight loss in OHS patients can reverse daytime hypercapnoea. (20) There are three principal causes explaining alveolar hypoventilation in obese subjects: high cost of the work of respiration, dysfunction of the respiratory centers, repeated episodes of nocturnal obstructive apnea. (21)

Martin and Sanders (22) suggest that the alveolar hypoventilation in OHS is a mixed disorder of "can't breathe" (chest wall and respiratory muscle disorder) and "won't breathe" (decreased ventilatory drive disorder). Obesity results in an increase in the work of breathing 
that reduces alveolar ventilation resulting in an elevated arterial $\mathrm{PaCO} 2$. This resets the set-point of the central nervous system chemoreceptors to a higher $\mathrm{PaCO} 2$, with consequent depression of ventilatory drive. Some evidence suggests that patients with OHS may have a measurable premorbid impairment of ventilatory chemoresponsiveness. This impairment is unlikely to be congenital as studies have shown no evidence of impaired ventilatory chemoresponsiveness in first degree relatives of patients with OHS. (23) The impairment of ventilatory chemoresponsiveness in OHS, therefore, is likely to be an acquired and reversible consequence of severe OSA.

In obese patients with chronic hypercapnoea, nocturnal polysomnography (NPSG) shows overlap of associated pulmonary disease with a ventilatory sleep disturbance in some cases. (24) Chronic airway obstruction has been demonstrated to play a major role in the development of daytime hypercapnoea in cases of OSA even in the absence of obesity (25). This condition is called "overlap syndrome" (26). However, subjects with OHS generally do not have airway obstruction. OHS should be distinguished from airway obstruction and other conditions that are commonly associated with hypercapnoea.

The discovery of the anti-obesity hormone leptin (the name is derived from the Greek "leptos" meaning "thin"), the product of the $o b$ gene, has fuelled a recent surge of interest in the mechanisms regulating mammalian fat stores. (27) Leptin is a modulator of respiratory drive in patients with OHS. (28) Leptin is a protein produced by adipose tissue that circulates to the brain and interacts with receptors in the hypothalamus to inhibit eating. Leptin circulates in the plasma in the free and protein bound forms. The hormone elicits appetite suppression and weight loss. Leptin-deficient mouse (ob/ob) develops OHS. (29) In obese humans, however, serum leptin is up to four times higher than in lean subjects, indicating that human obesity is associated with a central resistance to the weight-lowering effects of leptin. In patients with OHS, serum leptin is a better predictor of awake hypercapnoea in obesity than the BMI. Thus, adverse respiratory mechanics, diminished ventilatory response to a respiratory load, (30) and decreased leptin levels or leptin receptor density, may all attenuate hypercapnoeic ventilatory responsiveness, (31) and interact to promote the development of OHS.

\section{Diagnosis of OHS}

In general, OHS is seen in middle-aged men. However, some recent studies show female preponderance. (32) Most abnormalities in OHS are related to obesity such as higher hematocrit, higher total cholesterol, systemic hypertension, diabetes mellitus and more impaired pulmonary functions. OHS is associated with severe symptoms of sleep-related breathing disorders i.e. loud habitual snoring, nocturnal choking episodes, morning headaches and excessive daytime sleepiness (EDS). EDS due to sleep fragmentation caused by obstructive sleep apnea results in intellectual deterioration, personality and behaviour changes, depression and psychosis, deficits in thinking, perception, memory and ability to learn and more serious automobile and industrial accidents. (33) Another important feature of OHS is daytime hypercapnoea (chronic hypoventilation). Summary of clinical features of OHS are shown in table 3. In contrast to patients with simple OSA, dyspnoea, lower extremity edema, and low oxygen saturation during wakefulness, pulmonary hypertension and cor pulmonale are common. (34)

Chest radiograph and high resolution computed tomography (HRCT) is essential to exclude other causes of hypercapnoea. Pulmonary function testing commonly shows a restrictive defect due to obesity, may identify an obstructive abnormality due to associated airway disease and the flow volume loop may show upper airway obstruction (35) (Figure). Laboratory testing includes complete blood count for secondary erythrocytosis, thyroid function tests to exclude hypothyroidism and serum cortisol levels if Cushing's disease is suspected. An electrocardiogram (ECG) and 2-dimensional echocardiography (2 D ECHO) is useful to assess pulmonary hypertension and right ventricular and right atrial enlargement.

Pulse oximetry demonstrates hypoxemia during wakefulness. Patients with OHS have an elevated serum bicarbonate level due to the metabolic compensation for the chronic respiratory acidosis. Therefore, serum bicarbonate level may be a reasonable test to screen for hypercapnoea. It was recently shown (36) that the serum bicarbonate level combined with the severity of OSA can be used as clinical predictors of OHS in patients with morbid obesity and OSA.

Definitive diagnosis of OHS includes in-laboratory polysomnography (PSG) to demonstrate sleep related

Indian Journal of Sleep Medicine (IJSM), Vol. 2, No. 3, 2007 
breathing disorders and arterial blood gas (ABG) analysis necessary to confirm the presence and severity of daytime hypercapnoea. (37)This involves recording of multiple variables during sleep, including the neurological variables like electroencephalogram (EEG), electro-oclugram (EOG) and electromyogram (EMG) and cardiorespiratory variable like airflow, $\mathrm{O} 2$ saturation, snoring and heart rate. Limited sleep studies that measure relevant respiratory variables in the home may be useful if inlaboratory PSG is not possible. PSG showing apnoea hypopnoea index (AHI) $>5$ apnoeas per hour is considered positive for presence of sleep apnea (Figure). In addition, oxygen desaturation, changes in heart rate and rhythm, EEG arousals and periodic limb movements may also be seen.

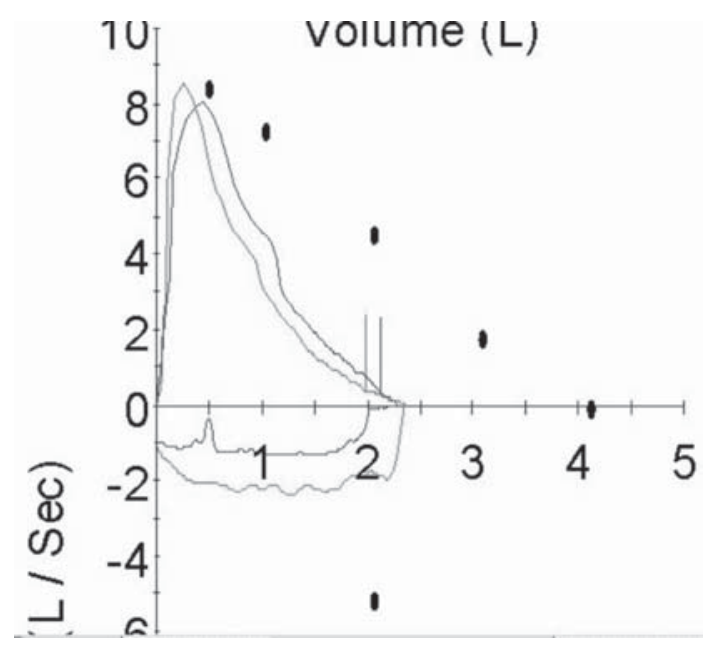

Fig 1: Flow volume loop in a case of obesity hypoventilation syndrome showing flattening of the inspiratory loop suggestive of variable extrathoracic upper airway obstruction.

\section{Treatment of OHS}

Treatment of OHS is consists of i) treatment of associated sleep apneas, ii) treatment of hypoventilation and iii) treatment of obesity. Treatment of sleep apnoea and nocturnal hypoventilation is by positive airway pressure (PAP) therapy. While autoadjusting PAP can be used in patients with simple OSA, laboratory based titration is preferred in patients with OHS to monitor associated hypoventilation. Nocturnal PAP therapy (CPAP or bilevel PAP) results in improvement in chronic daytime hypercapnoea and hypoxia as well. Nocturnal non invasive ventilation in the form of bi-level PAP may be required for most patients to take care of sleep apnoea and hypoventilation.

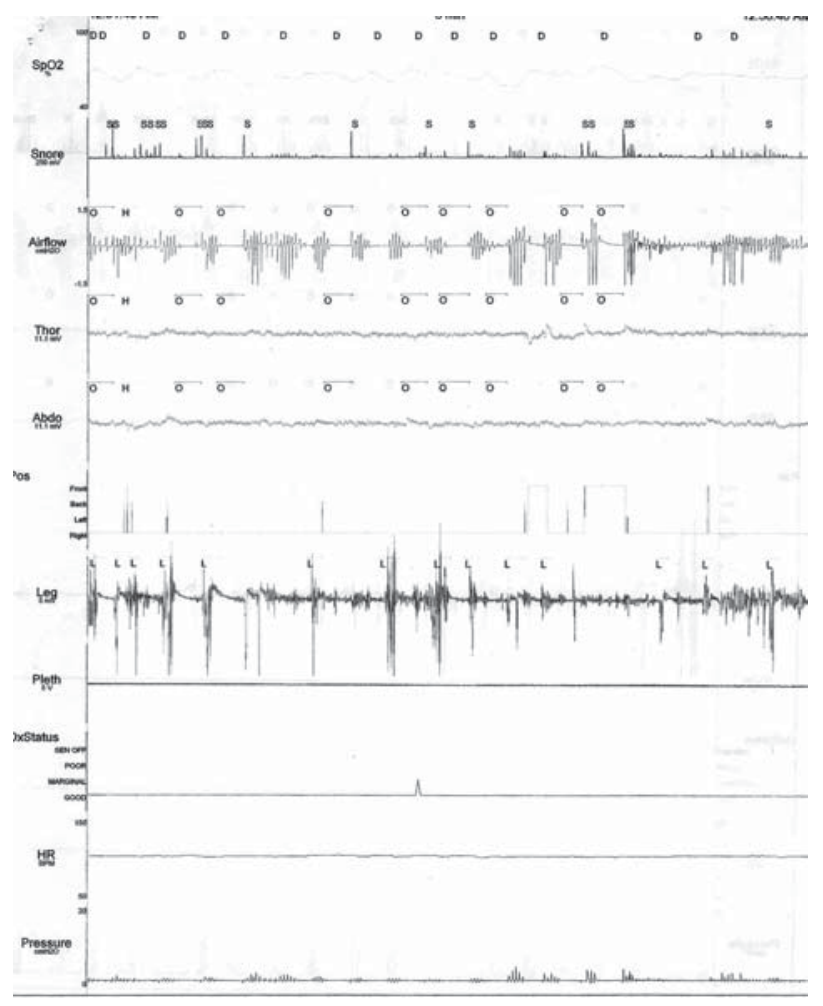

Fig 2: Nocturnal polysomnography with cardio-respiratory variables showing obstructive apnoeas and hypopnoeas, oxygen desaturation and periodic limb movements.

Table 1: Proposed WHO Classification of Overweight

\begin{tabular}{|l|l|l|}
\hline BMI* $^{*}$ kg m2) & WHO classification & Description \\
\hline$<18.5$ & Underweight & Thin \\
\hline $18.5-24.9$ & - & Normal \\
\hline $25.0-29.9$ & Grade 1 overweight & Overweight \\
\hline $30.0-39.9$ & Grade 2 overweight & Obesity \\
\hline e"40.0 & Grade 3 overweight & Morbid obesity \\
\hline
\end{tabular}

${ }^{*} \mathrm{BMI}$ is the weight in kilograms divided by the square of the height in metres.

Table 2: Diagnostic criteria for obesity hypoventilation syndrome

\begin{tabular}{|ll|}
\hline - & Body mass index $>30 \mathrm{~kg} / \mathrm{kg} 2$ \\
\hline - & Daytime PaCO2 $>45 \mathrm{~mm} \mathrm{Hg}$ \\
\hline - & Associated sleep-related breathing disorder \\
\hline - & $\begin{array}{l}\text { (obstructive sleep apnea-hypopnea syndrome or sleep } \\
\text { hypoventilation or both) }\end{array}$ \\
\hline - & Absence of other known causes of hypoventilation \\
\hline
\end{tabular}


Table 3: Clinical features of Obesity Hypoventilation Syndrome

\begin{tabular}{|l|}
\hline Symptoms \\
\hline - Loud snoring \\
- Disrupted sleep \\
- Nocturnal gasping and choking \\
- Ditnessed apnea \\
- Neuropsychiatric features \\
- PAH/ Cor Pulmonale \\
\hline Physical findings \\
\hline - Obesity (BMI Wt in Kg/ Ht in $\left.\mathrm{mt}^{2}>30\right)$ \\
- Features of associated problems like hypothyroidism, \\
- Cushing's syndrome \\
- Systemic hypertension \\
- Crowded posterior airway \\
- Short, thick neck \\
- May have associated small, receding jaw \\
- Upper airway obstruction (UAO) on flow volume loop \\
- Polycythemia, hematocrit greater than $50 \%$ \\
- Reduced PaO2 and elevated PaCO2 during sleep \\
- Elevated PaCO2 during awake hours \\
- Pulmonary Hypertension/ Cor Pulmonale \\
\hline
\end{tabular}

Table 4: Treatment of OHS

\begin{tabular}{|c|c|}
\hline & $\begin{array}{l}\text { Behavioral modifications } \\
\text { Diet modification } \\
\text { Excercise }\end{array}$ \\
\hline$\bullet$ & $\begin{array}{l}\text { Positive Airway Pressure (PAP) therapy } \\
\text { Nasal continuous airway pressure (n-CPAP) } \\
\text { Bilevel positive airway pressure (Bi-PAP) }\end{array}$ \\
\hline & $\begin{array}{l}\text { Pharmacotherapy } \\
\text { Medroxyprogesterone, carbonic anhydrase inhibitor }\end{array}$ \\
\hline & $\begin{array}{l}\text { Surgical therapy } \\
\text { Bariatric Surgery } \\
\text { Tracheostomy }\end{array}$ \\
\hline
\end{tabular}

If PAP therapy alone fails to achieve the desired results, oxygen supplementation for persisting hypoxemia and pharmacotherapy for respiratory stimulation must be considered. Medroxyprogesterone in a dose of 60 $\mathrm{mg} /$ day is useful for treatment of hypoventilation in patients with OHS. It increases the ventilatory response to hypercapnoea and also reduces the AHI. $(38,39)$ Favourable response to medroxyprogesterone can be predicted by the ability to drop the $\mathrm{PaCO} 2$ by at least 5 $\mathrm{mm} \mathrm{Hg}$ with voluntary hyperventilation. (40) Medroxyprogesterone however can increase the risk of venous thromboembolism. (41) Alternately acetazolamide in a dose of $250 \mathrm{mg} /$ day may be used to reduce the serum bicarbonate level and the resulting metabolic acidosis increases the minute ventilation and reduces the $\mathrm{PaCO} 2$. (42)

Weight loss is the only cure for OHS. It is associated with improvements in blood gases, sleep-related breathing disorders and pulmonary hypertension. (43) Unfortunately, weight loss is often difficult to achieve by means of diet and exercise. Bariatric surgery to treat obesity may be necessary and should be offered to patients who are appropriate surgical candidates. The National Institutes of Health, US consensus guidelines recommend surgical treatment for patients with a BMI greater than $35 \mathrm{~kg} / \mathrm{m}^{2}$ and an obesity-related co morbid condition (including OHS) or patients with a body mass index greater than $40 \mathrm{~kg} / \mathrm{m}^{2}$. (44) The surgical options (45) available can be grouped into 2 categories based on their weight loss mechanism. Gastric restrictive procedures include vertical banded gastroplasty (VBG), adjustable gastric banding (AGB), and Roux-en-Y gastric bypass (RYGB). The procedures causing malabsorption include biliopancreatic diversion (BPD) and biliopancreatic diversion with duodenal switch (BPD-DS). All of the procedures have been successful in improving the co morbidities associated with obesity. The most commonly performed procedure is RYGB is generally performed laparoscopically and has the best safety, efficacy, and durability, and it has been shown to be superior to AGB. All the procedures must be performed by experienced surgeons and require long-term dietary compliance and careful nutritional follow-up. (45) Finally, tracheostomy is an option to treat ppatients with the obstructive form of OHS. (46) However, improvement after several nights sleep with a nasopharyngeal tube in place should be demonstrated before such invasive form of therapy is attempted. $(47,48)$

\section{References}

1. International obesity taskforce [IOTF]. Available: http:// www.iotf.org/millennium.asp (accessed 1November 2007).

2. World Health Organization (WHO). Available: www.who.int/ mediacentre/factsheets/fs311/en/index.html

Indian Journal of Sleep Medicine (IJSM), Vol. 2, No. 3, 2007 
3. Sturm R. Increases in clinically severe obesity in the United States, 1986-2000. Arch Intern Med 2003; 163:21462148 .

4. Prentice A, Webb F. Obesity amidst poverty. Int J Epidemiol 2006; 35:24-30.

5. Mudar G. Asia grapples with obesity epidemics. BMJ $2003 ; 326: 515$

6. Kessler R, Chaouat A, Schinkewitch P, et al. The obesity hypoventilation syndrome revisited: a prospective study of 34 consecutive cases. Chest 2001; 120:369-376

7. Kimura $\mathbf{H}$, Eto $H$, Tatsumi $K$, et al. The prognosis and treatment effects in patients with obesity-hypoventilation syndrome and obstructive sleep apnea syndrome. The reports of the Respiratory Failure Research Group in Japanese Ministry of Health and Welfare. 88-90, 2000 (in Japanese).

8. Berg G, Delaive K, Manfreda J, Walld R, Kryger MH. The use of health-care resources in obesity-hypoventilation syndrome. Chest $2001 ; 120$ : 377-383.

9. Kopelman PG. Obesity as a medical problem. Nature 2000;404:635-643.

10. Deepa R, Sandeep S, Mohan V. Abdominal obesity, visceral fat and type 2 diabetes - 'Asian Indian phenotype'. In: Mohan V, Gundu Rao, eds. Type 2 diabetes in South Asians: Epidemiology, risk factors and prevention. Jaypee Brothers Medical publishers, 2006; 138-52.

11. Dickens Charles The Posthumous Papers of the Pickwick Club. The Macmillan Company 1904.

12. Bickelmann AG, Burwell CS, robin ED, Whaley RD. Extreme obesity associated with alveolar hypoventilation; a Pickwickian syndrome. Am J Med. 1956;21:811-818.

13. Achincloss JH Jr, Cook E, Renzetti AD. Clinical and physiological aspects of a case of polycythemia and alveolar hypoventilation. J Clin Invest 1955; 34: 1537-1545.

14. Bickelmann AG, Burwell CS, Robin ED, Whaley RE. Extreme obesity with alveolar hypoventilation: a Pickwickian syndrome. Am J Med 1956; 121: 811-818.

15. Weitzenblum E, Kessler R, Chaouat A. [Alveolar hypoventilation in the obese: the obesity-hypoventilation syndrome] [Article in French]. Rev Pneumol Clin. 200;58:83-90.

16. The Reports of the Respiratory Failure Research Group in Japanese Ministry of Health and Welfare. 1-11, 1998 (in Japanese).

17. Mokhlesi B, Tulaimat A, Faibussowitsch I, et al. Obesity hypoventilation syndrome: prevalence and predictors in patients with obstructive sleep apnea. Sleep Breath 2007; $11: 117-124$.

18. Akashiba T, Akahoshi T, Kawahara S, et al. Clinical characteristics of obesity-hypoventilation syndrome in Japan: a multi-center study. Intern Med 2006; 45:1121-1125

19. American Academy of Sleep Medicine. Sleep-related breathing disorders in adults: recommendations for syndrome definition and measurement techniques in clinical research: the report of an American Academy of Sleep
Medicine task force. Sleep 1999; 22:667-689.

20. Sugerman, HJ, Fairman, PR, Sood, RK, et al. Long-term effects of gastric surgery for treating respiratory insufficiency of obesity. Am J Clin Nutr 1992; 55,597S-601S.

21. Berger KI, Ayappa I, Chatr-Amontri B, Marfatia A, Sorkin IB, Rapoport DM, Goldring RM. Obesity hypoventilation syndrome as a spectrum of respiratory disturbances during sleep. Chest. 2001;120:1231-8.

22. Martin R. TJ, Sanders MH. Chronic alveolar hypoventilation: a review for the clinician. Sleep 1995; 18,617-634.

23. Jokic $\mathbf{R}$, Zintel T, Sridhar G, Gallagher CG, Fitzpatrick M F. Ventilatory responses to hypercapnia and hypoxia in relatives of patients with the obesity hypoventilation syndrome Thorax 2000;55:940-945

24. Bradley TD, Rutherford R, Lue F, et al. Role of diffuse airway obstruction in the hypercapnia of obstructive sleep apnea. Am Rev Respir Dis 134: 920-924, 1986.

25. Flenley DC. Chronic obstructive pulmonary disease. in: Principles and Practice of Sleep Medicine, Kryger MH, Roth R, Demment W, Eds. WB Saunders, Philadelphia, 1989, 601-610.

26. Fitzpatrick $\mathbf{M}$. Leptin and the obesity hypoventilation syndrome: a leap of faith? Thorax. 2002;57:75-6.

27. Yee B J., Cheung J, Phipps P, Banerjee D, Piper A J, Grunstein R R. Treatment of Obesity Hypoventilation Syndrome and Serum Leptin. Respiration 2006;73:209-212.

28. Tankersley. C, Kleeberger S, Russ B, et al. Modified control of breathing in genetically obese (ob/ob) mice. J Appl Physiol $1996 ; 81: 716-723$

29. Greenberg HE, Scharf SM. Depressed ventilatory load compensation in sleep apnea: reversal by nasal CPAP. Am Rev Respir Dis 1993;148:1610-1615.

30. O'Donnell CP, Schaub CD, Haines AS, et al. Leptin prevents respiratory depression in obesity. Am J Respir Crit Care Med 1999;159:1477-1484.

31. O'Donnell CP, Tankersley CG, Polotsky, VP, et al. Leptin obesity, and respiratory function. Respir Physiol 2000 119:163-170.

32. Nowbar S, Burkart KM, Gonzales R, et al. Obesityassociated hypoventilation in hospitalized patients: prevalence, effects, and outcome. Am J Med 2004; 116:17.

33. Haraldsson PO, Akerstedt T. Drowsiness-greater traffic hazard than alcohol: causes, risks and treatment. Lakartidningen $2001 ; 98: 3018-3023$.

34. Ahmed $Q$, Chung-Park $M$, Tomashefski JF Jr. Cardiopulmonary pathology in patients with sleep apnea/ obesity hypoventilation syndrome. Hum Pathol 1997; 28:264-269.

35. Shepard JW, Burger CD. Nasal and oral flow-volume loops in normal subjects and patients with obstructive sleep apnea Am Rev Respir Dis. 1990;142:1288-93.

36. Mokhlesi B, Tulaimat A, Faibussowitsch I, et al. Obesity hypoventilation syndrome: prevalence and predictors in patients with obstructive sleep apnea. Sleep Breath 2007; 
$11: 117-124$.

37. Mokhlesi B, Tulaimat A. Recent Advances in Obesity Hypoventilation Syndrome Chest. 2007; 132:1322-1336.

38. Sutton FD Jr, Zwillich CW, Creagh CE, et al. Progesterone for outpatient treatment of Pickwickian syndrome. Ann Intern Med 1975; 83:476-479

39. Kimura H, Tatsumi K, Kunitomo F, et al. Progesterone therapy for sleep apnea syndrome evaluated by occlusion pressure responses to exogenous loading. Am Rev Respir Dis 1989; 139:1198-1206.

40. Skatrud JB, Dempsey JA, Bhansali P, et al. Determinants of chronic carbon dioxide retention and its correction in humans. J Clin Invest 1980; 65:813-821.

41. Poulter NR, Chang CL, Farley TM, et al. Risk of cardiovascular diseases associated with oral progestagen preparations with therapeutic indications. Lancet 1999; 354:1610.

42. Teppema LJ, Dahan A. Acetazolamide and breathing: does a clinical dose alter peripheral and central $\mathrm{CO}(2)$ sensitivity? Am J Respir Crit Care Med 1999; 160:1592-1597.

43. Olson AL, Zwillich C. The obesity hypoventilation syndrome. Am J Med 2005;1 18:948-56.

44. Gastrointestinal surgery for severe obesity: National Institutes of Health Consensus Development Conference Statement. American Journal of Clinical Nutrition 1992; 55: 615S-619S.

45. Johnson W, DeMaria E. Surgical treatment of obesity. Curr Treat Options Gastroenterol 2006; 9: 167-74.

46. Kim SH, Eisele DW, Smith PL, et al. Evaluation of patients with sleep apnea after tracheotomy. Arch Otolaryngol Head Neck Surg 1998; 124:996-1000.

47. Morgan EJ, Zwillich CW. The obesity-hypoventilation syndrome. West J Med 1978;129:387-393.

48. Kuhlo W, Doll E: Pulmonary hypertension and the effect of tracheotomy in a case of pickwickian syndrome. Bull PhysioPath Resp 1972; 8:1205-1216. 